Original

\title{
Influence of surface roughness on crack formation in a glass-ceramic bonded to a resin composite base
}

\author{
Takatsugu Yamamoto, Rie Nishiura and Yasuko Momoi \\ Department of Operative Dentistry, Tsurumi University School of Dental Medicine, Kanagawa, Japan
}

(Received 8 May and accepted 10 July 2006)

\begin{abstract}
The objective of the present study was to assess the influence of the roughness of a loaded surface on crack formation in a mica-based glass-ceramic bonded to a resin composite base. Five different surface roughnesses were created on glass-ceramic discs by serial wet-grinding with silicone carbide abrasives. The thicknesses of the ceramic discs were $1.50 \pm 0.01$ $\mathrm{mm}$. Resin composite discs were bonded to the ceramic surfaces opposite to the ground surfaces using an adhesive resin composite cement and a silane coupling agent. A compressive load was then applied at the center of the ground ceramic surface. The loads at initial radial and cone crack formations in the ceramic were measured macroscopically. In three of the five groups, the initial radial crack formations could not be observed due to the high roughness of these surfaces. Statistical analysis was performed using Student's $t$ test for initial radial cracks and one-way ANOVA for the cone cracks. There were no significant differences between the two groups for the initial radial cracks or among the five groups for the cone cracks $(P<0.05)$. The roughness of the loaded surface had no influence on crack formation in the bonded mica-based glassceramic. (J. Oral Sci. 48, 125-130, 2006)
\end{abstract}

Keywords: surface roughness; crack formation; glassceramic.

Correspondence to Dr. Takatsugu Yamamoto, Department of Operative Dentistry, Tsurumi University School of Dental Medicine, 2-1-3, Tsurumi, Tsurumi-ku, Yokohama, Kanagawa 230-8501, Japan

Tel: +81-45-581-1001 ext. 8550

Fax: +81-45-573-9599

E-mail: yamamoto-tk@tsurumi-u.ac.jp

\section{Introduction}

As dental patients are becoming increasingly concerned about oral esthetics, ceramics and resin composites are frequently being applied to tooth-colored metal-free indirect restorations. In general, ceramics have higher mechanical strength, elastic modulus, and chemical inertness than resin composites (1). One of the clinical shortcomings of ceramics, however, is the difficulty involved in surface polishing. Autoglazing has been effective as a technique by which to overcome surface polishing in porcelains (2), and add-on glazing porcelains are used to smooth the surfaces of mold-injectable ceramics. However, certain characteristics of mold-injectable ceramics are lost by covering the ceramic surface with an add-on porcelain, and rotary polishing is used to achieve the characteristics of ceramics in the oral environment. Yamamoto et al. (3) reported that the surface roughness (Ra) of a mica-based glass-ceramic polished using rotary instruments from the manufacturer was approximately $1.0 \mu \mathrm{m}$, whereas Ishizawa and Yamamoto (4) stated that the roughness of a diopsidebased glass-ceramic was less than $1 \mu \mathrm{m}$ without polishing. Although the surface roughness of the tensile surface is known to affect the mechanical properties of ceramic materials (5-7), few studies have examined the influence of loaded surface roughness on ceramic properties.

Remarkable progress in the field of polymeric materials has led to the widespread clinical use of adhesive restorative materials. Achieving excellent dentinal sealing is important for restoring both vital and non-vital teeth. The resin coating technique is used for indirect restorations in which the prepared dentinal surface is fully covered with a dentin adhesive and a flowable resin composite prior to impressiontaking. Not only the dentinal sealing but also the bond strength of resin cement is improved with this technique $(8,9)$. Mount and Ngo (10) have proposed a new cavity 
design in which the cavity margin is prepared in an adhesive cavity base. Yamamoto et al. (11) investigated the stress distributions in teeth restored with glass-ceramic restoratives of which cavities were prepared in resin composite bases. The authors stated that preparing the entire cavity in the resin composite base would be acceptable clinically and was effective for preventing excess tooth reduction in indirect restorations. Therefore, in order to perform minimally invasive indirect restoration, a condition whereby the ceramic restorative is wholly supported by the adhesive resin composite base should be produced clinically. Accordingly, it is essential to investigate the fracture mechanics of ceramic materials bonded to a resin composite base.

The objective of this study was to investigate the influence of the roughness of a loaded surface on crack formation in a mica-based glass-ceramic bonded to a resin composite base, in order to test the hypothesis that the roughness of the loaded surface affects crack formation in the bonded ceramic.

\section{Materials and Methods}

Thirty-five mica-based glass-ceramic discs (OCC, lot no. 96 1012, Olympus Optical Co., Tokyo, Japan) were processed from smooth wax patterns $14 \mathrm{~mm}$ in diameter and $1.6 \mathrm{~mm}$ thick according to the manufacturer's instructions. The ceramic discs were divided randomly into five equal groups (Groups 1 - 5). In order to create various surface roughnesses on the discs, one flat surface of each disc was serially wet-ground under tap water using up to 180 (Group 1), 220 (Group 2), 400 (Group 3), or 1200 grit $\mathrm{SiC}$ abrasive paper (Group 4), or $6-\mu \mathrm{m}, 3-\mu \mathrm{m}$ and $1-\mu \mathrm{m}$ diamond paste (Group 5). For Groups 1 - 4, the surface grinding was performed under finger pressure for 10 passes. For Group 5, the diamond paste polishing was performed for 5 min using each paste after $\mathrm{SiC}$ abrasion. The thickness of all discs was adjusted to $1.5 \mathrm{~mm}$. Parallelism between the two flat surfaces was confirmed by thickness measurement at three different points for

Table 1 Ra values $(\mu \mathrm{m})$, loads $(\mathrm{N})$ at formations of initial radial crack and cone crack and standard deviations (in brackets)

\begin{tabular}{llcc}
\hline Group & Ra & Initial radial crack & Cone crack \\
\hline Group 1 & $0.90(0.12)$ & $----^{*}$ & $2826(765)$ \\
Group 2 & $0.49(0.09)$ & $----*$ & $2530(604)$ \\
Group 3 & $0.19(0.03)$ & $---*$ & $2211(774)$ \\
Group 4 & $0.10(0.01)$ & $811(188)$ & $2266(504)$ \\
Group 5 & $0.05(0.01)$ & $820(246)$ & $2862(780)$ \\
\hline
\end{tabular}

Loads connected by vertical lines are not significantly different at $P<0.05$.

*Load was unable to be measured due to roughness in loaded surface. each disc. The roughness (Ra) of the ground surface was measured twice in perpendicular directions at the center of each disc using a surface recorder (Surfcom 120A, Tokyo Seimitsu, Tokyo, Japan). The conditions for the roughness measurement were: $\lambda \mathrm{c} 0.8 \mathrm{~mm}$, probe radius 2 $\mu \mathrm{m}$, measuring load $0.004 \mathrm{~N}$, measuring length $5 \mathrm{~mm}$, depth magnification $\times 1,000$, lateral magnification $\times 20$, and feed rate $0.1 \mathrm{~mm} / \mathrm{sec}$.

Thirty-five resinous discs $15 \mathrm{~mm}$ diameter and $2 \mathrm{~mm}$ thick were fabricated in a silicone mold using a dualcured resin composite for the core foundation (Clearfil DC Core, lot no. universal 0159; catalyst 0165, Kuraray Medical, Tokyo, Japan). The discs were lightly wet-ground using 600 grit $\mathrm{SiC}$ abrasive paper under finger pressure for 10 passes. The discs were then cleaned ultrasonically in water for $5 \mathrm{~min}$. Parallelism was confirmed using the method described above.

The non-ground ceramic surfaces and the ground resin surfaces were cleaned with $40 \%$ phosphoric acid gel (Ketchant, lot no. 251, Kuraray Medical) for $5 \mathrm{sec}$. The surfaces were then thoroughly rinsed with a water spray for $10 \mathrm{sec}$ and air-dried with an air syringe. The ceramic discs and the resin discs were bonded under a static pressure of $19.6 \mathrm{~N}$ using a combination of an adhesive primer, a silane coupling agent, and a resin composite cement (Clearfil SE Bond Primer, lot no. 0180AA, Clearfil Porcelain Bond Activator, lot no. 0112AB, and Panavia F, lot no. A paste: 00052A; B paste: 00028A, Kuraray Medical). The bonded specimens were stored in water at $37^{\circ} \mathrm{C}$ for $48 \mathrm{~h}$.

The trilayer specimens consisting of the ceramic, the cement and the base were supported on a flat rigid surface, and a compressive load was applied to the center of the ceramic surfaces at a cross-head speed of $0.2 \mathrm{~mm} / \mathrm{min}$ using a Shimadzu Autograph AG-500A (Shimadzu, Tokyo, Japan) until radial cracks opening onto the loaded surface were produced. In order to simulate severe occlusal contact, the diameter of the loading pin was $3 \mathrm{~mm}$ (12). The loads at which initial radial and cone cracks appeared were measured macroscopically by two observers, as no obvious changes appeared in the loading curve upon crack initiation. The resulting data were analyzed statistically by Student's $t$ test or one-way ANOVA at a level of significance of 0.05 . Following the loading test, the cracked/fractured specimens were observed using a light microscope (SZX9, Olympus Optical Co., Tokyo, Japan) and a scanning electron microscope (JSM 5600 LV, JEOL, Tokyo, Japan).

\section{Fracture load}

\section{Results}

Table 1 presents the mean Ra values, the mean loads at 


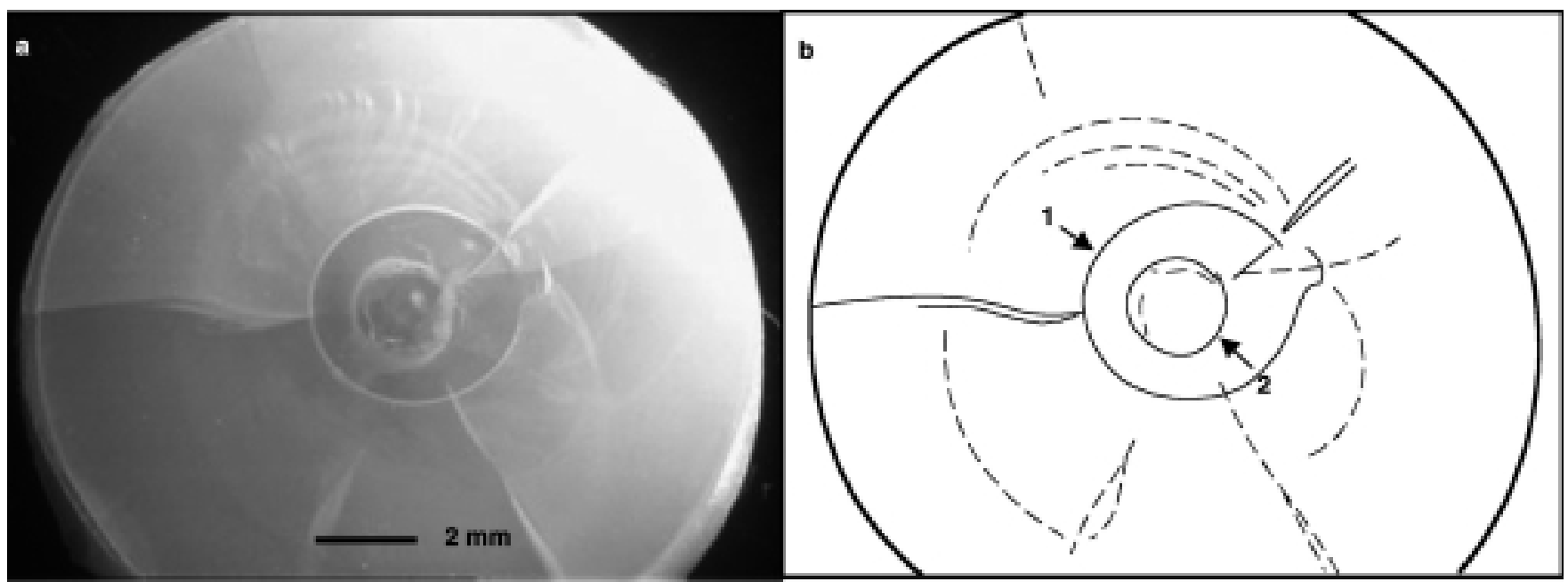

Fig. 1 a (left): Light micrograph of loaded specimen. Radial cracks and circular cracks are evident.

b (right): Schematic drawing of Fig. 1a. Broken lines and solid lines indicate subsurface cracks and opening cracks, respectively.

initial radial and cone crack formation and the standard deviations. Fourteen of the 35 specimens were fractured into segments during the loading.

The maximum and minimum Ra values were obtained in Group 1 (180 grit) and Group 5 (1/4 $\mu \mathrm{m}$ diamond paste), respectively. Different Ra values were observed in the five groups, as expected.

In Groups 1 - 3, it was impossible to measure the loads at initial radial crack formation because the initial radial cracks were invisible due to poor transmissivity of the ceramic surface generated by the roughness. On the other hand, macroscopic measurements were possible for Groups 4 and 5. The mean loads in Groups 4 and 5 were similar, and no significant difference between them was observed by Student's $t$-test $(P=0.9531)$.

At the point of cone crack formation, all of the groups showed loads above $2000 \mathrm{~N}$. The means ranged from $2211 \mathrm{~N}$ in Group 3 to $2862 \mathrm{~N}$ in Group 5. One-way ANOVA revealed no significant differences among the five groups $(P=0.4526)$.

\section{Microscopic observation}

Figure 1a shows a light micrograph of the loaded ceramic surface. Radial and circular cracks can be seen in the specimen. Fig. 1b is a schematic drawing of Fig. 1a in which broken lines and solid lines indicate subsurface cracks and cracks opening onto the loaded surface, respectively. The subsurface cracks and the opening cracks were found to include both radial and circular cracks. The diameters of the two opening circular cracks (arrows 1 and 2 in Fig. 2B) were larger and smaller than that of the loading pin $(3 \mathrm{~mm}$ diameter), respectively. The larger crack appeared as a sharp line and seemed to propagate with spreading toward the

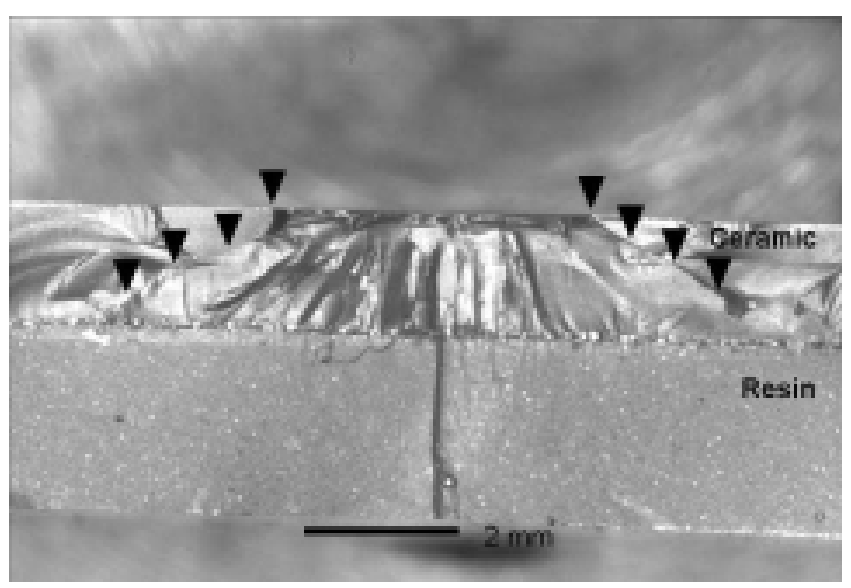

Fig. 2 Light micrograph of fractured section. The section has been gold-coated.

ceramic/resin interface. In contrast, the smaller crack appeared as a vague and bold line without spreading.

Figure 2 shows a light micrograph of the fractured section. Inclined cracks (triangles) are observed to propagate toward the ceramic/resin interface. In addition, the area between these inclined cracks is irregular. Fig. 3 is a magnified SEM image of Fig. 2. Numerous cracks can be seen running vertically from the ceramic/resin interface to the loaded surface. Fig. 4 shows a section of fractured ceramic just beneath the loaded area. Many scrape-like marks (arrows) and two obscure bands (triangles) are evident. The scrape-like marks are oriented almost parallel to the direction of loading, while the bands for which the surface appears to be smooth are believed to be perpendicular to the loading direction. No obvious differences were observed among the aspects of the fractured sections in the five groups. 


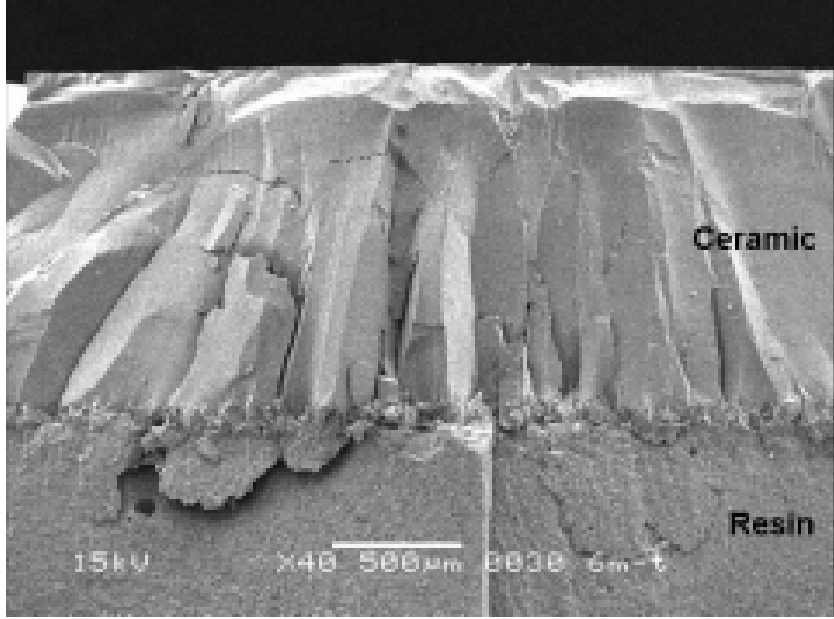

Fig. 3 SEM image of fractured section in Fig. 2.

\section{Discussion}

Several investigators have measured the fracture loads of ceramics supported by certain substrates (e.g., tooth, epoxy resin, and resin composite) (13-20). The fracture loads in previous studies of ceramics were those recorded at catastrophic fracture. In general, unsupported ceramics show abrupt fracture due to their brittle nature; however, the fracture mechanisms change when the ceramics are supported (21-23). Tsai et al. (19) investigated the fracture mechanisms of a trilayered specimen consisting of micabased glass-ceramic/resin composite cement/epoxy resin. They found that initial radial cracks were produced within the ceramic/cement interface under the loaded area, followed by cone crack formation ("Hertzian cone" fractures) from the loaded surface. In the present study, radial/circular, subsurface/opening cracks were observed in the top view (see Fig. 1). The radial cracks were initial radial cracks and median-radial cracks $(24,25)$. The larger circular crack (arrow 1 in Fig. 1b) was the initiation site of the cone crack, and the smaller circular crack (arrow 2 in Fig. 1b) was considered to be composed of transverse cracks extending upward from the ceramic/resin interface (21-23). The initial radial cracks and the transverse cracks were the same, and the difference in the crack designation originates from the direction of observation (19,21-23). Consequently, in the present study, three types of cracks were produced in the following order: initial cracks, cone cracks, and median-radial cracks.

When a load is applied to a ceramic bonded to resinous material, apparent tensile stress is created in the ceramic because its elastic modulus is higher than that of the resin (26). Yamamoto et al. (11) evaluated stress distributions in minimally invasive ceramic inlay restorations, as described in the Introduction. They reported that the major

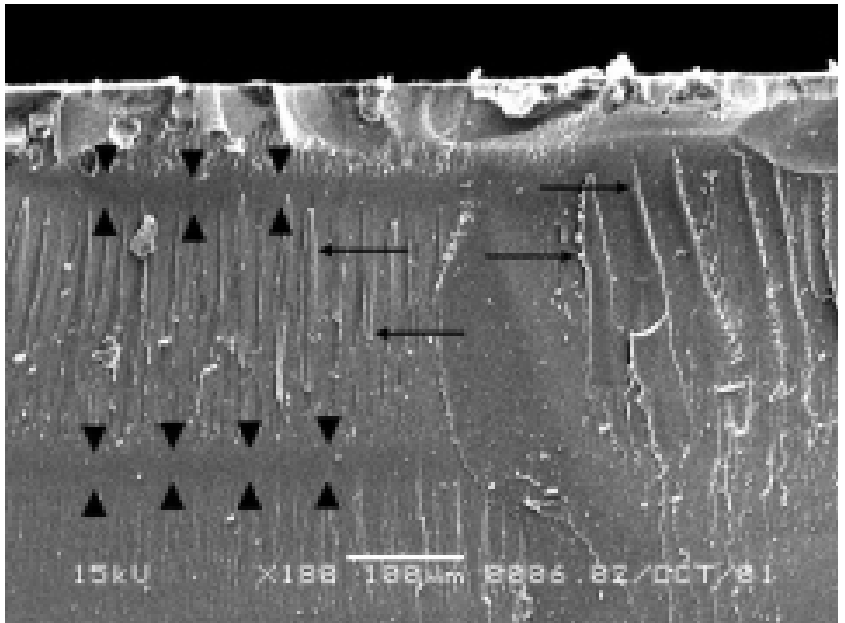

Fig. 4 SEM image of fractured section just beneath the loaded area.

tensile stress was generated within the ceramic at the ceramic/resin cement interface. Deng et al. (27) revealed that radial cracks were initiated from the undersurface of a ceramic in contact with polymer in a ceramic/ceramic/ polymer trilayer. Although it was impossible to define the crack initiation site in Figs. 2 and 3 because of collapse of the typical markings of crack initiation and propagation $(19,28,29)$ due to application of the load until the formation of median-radial cracks, the initial cracks were considered to initiate at the ceramic/resin interface and to propagate radially (initial radial crack) and upward (transverse crack) $(12,19,22,23)$. No cracking sound was audible in this study, in contrast to the study by Tsai et al. (19), and this was why load measurement had to be performed macroscopically, making some of the data unmeasurable. The difference between the present study and that of Tsai et al. can be explained by the scrape-like marks and the obscure bands shown in Fig. 4. These marks and bands appeared to be hackle and mirror/mist regions, respectively, and they appeared mutually. The appearance of these fracture surface features was considered to indicate gradual crack propagation. Therefore, no cracking sound was audible because the cracks grew slowly. Irregularities indicating the initial cracks (transverse cracks) were produced between the cone cracks (see Fig. 2). This phenomenon can be used to explain the difference in diameter of the two circular cracks (see Fig. 1).

Cone cracks are initiated at surface flaws in the loaded surface due to high tensile stress generated around the loaded area, and the cone cracks propagate along the stress plane (30). We hypothesized that the roughness of the loaded surface affected cone crack formation. However, this hypothesis was rejected because no significant differences were found among the five groups. In light 
micrographs (Fig. 1), the diameter of the larger circular crack was wider than that of the loading pin $(\varnothing 3 \mathrm{~mm})$, and the crack appeared to grow downward with spreading. These findings were supported by images of the fractured section (Fig. 3), in which the distance between the initiation sites of the cone cracks (two triangles on the loaded surface) exceeded $3 \mathrm{~mm}$ and the cracks ran obliquely toward the ceramic/resin interface.

Median-radial cracks are generally produced under sharp indentation conditions. However, in the present study, they were produced even with blunt indentation. Jung et al. (23) demonstrated finite element-generated stress contours in a ceramic/resin bilayer specimen in contact with a tungsten sphere. They revealed that the tensile stresses were generated outside the contact area on the loaded surface. Their contours must have indicated median-radial crack formation under blunt indentation conditions. The formation of median-radial cracks was consistent with their FEA study.

In the present study, the loads at initial radial cracks in the trilayer specimens exceeded those during mastication and swallowing ( 5 to $360 \mathrm{~N}$ ) (12). These results appear to indicate that the fracture strength of a mica-based glassceramic bonded to a resin composite would be sufficient for functioning in the oral environment, and that a glassceramic can be applied to a minimally invasive toothcolored restoration (11). However, the strength degradation of a mica-based glass-ceramic is more conspicuous than that of other ceramic materials once the materials have received surface damage or are subjected to contact fatigue testing (31-33). Recently, a new type of cone crack known as an inner cone crack was reported by Zhang et al. $(34,35)$. Such inner cone cracks were observed within an area subjected to cyclic loading in water, and propagated faster and more deeply than conventional cone cracks. These inner cones would also be a factor inducing strength degradation. Clinical use of this mica-based material will require improvements in its damage tolerance.

\section{References}

1. O'Brien WJ (1997) Tabulated values of physical and mechanical properties. In Dental materials and their selection. 2nd ed, Quintessence Publishing, Carol Stream, 331-399

2. Anusavice KJ (1996) Dental ceramics. In Phillips' science of dental materials. 10th ed, WB Saunders, Philadelphia, 583-618

3. Yamamoto T, Sampei T, Takamizu M, Kohno A (2001) Influence of surface treatment on flexural strength of a glass-ceramic. J Dent Res 80, 558 (abstract \#255)
4. Ishizawa N, Yamamoto T, Momoi Y (2004) Surface roughness of a diopside-based glass-ceramic. Nihon Shika Hozongaku Zasshi 47 (Spring Issue), 168 (abstract \#P-114) (in Japanese)

5. Campbell SD, Kelly JR (1989) Influence of surface preparation on the strength and surface microstructure of a cast dental ceramic. Int J Prosthodont 2, 459-466

6. Rosenstiel SF, Baiker MA, Johnston WM (1989) Comparison of glazed and polished dental porcelain. Int J Prosthodont 2, 524-529

7. Fairhurst CW, Lockwood PE, Ringle RD, Thompson WO (1992) The effect of glaze on porcelain strength. Dent Mater 8, 203-207

8. Momoi Y, Akimoto N, Kida K, Yip KH, Kohno A (2003) Sealing ability of dentin coating using adhesive resin systems. Am J Dent 16, 105-111

9. Nikaido T, Cho E, Nakajima M, Tashiro H, Toba S, Burrow MF, Tagami J (2003) Tensile bond strengths of resin cements to bovine dentin using resin coating. Am J Dent 16, 41A-46A

10. Mount GJ, Ngo H (2000) Minimal intervention: advanced lesions. Quintessence Int 31, 621-629

11. Yamamoto T, Takeishi S, Hara M, Momoi Y (2004) Finite element analysis of minimally invasive toothcolored indirect restorations. In Proceedings of conference on scientific insights into dental ceramics and photopolymer networks, Vol 18, Academy of Dental Materials, 205 (abstract \#56)

12. Kelly JR (1999) Clinically relevant approach to failure testing of all-ceramic restorations. J Prosthet Dent 81, 652-661

13. Friedlander LD, Munoz CA, Goodacre CJ, Doyle MG, Moore BK (1990) The effect of tooth preparation design on the breaking strength of Dicor crowns: Part 1. Int J Prosthodont 3, 159-168

14. Scherrer SS, de Rijk WG (1992) The effect of crown length on the fracture resistance of posterior porcelain and glass-ceramic systems. Int J Prosthodont 5, 550-557

15. Scherrer SS, de Rijk WG (1993) The fracture resistance of all-ceramic crowns on supporting structures with different elastic moduli. Int J Prosthodont 6, 462-467

16. McCormick JT, Rowland W, Shillingburg HT Jr, Duncanson MG Jr (1993) Effect of luting media on the compressive strengths of two types of all-ceramic crown. Quintessence Int 24, 405-408

17. Scherrer SS, de Rijk WG, Belser UC, Meyer JM (1994) Effect of cement film thickness on the fracture resistance of a machinable glass-ceramic. Dent 
Mater 10, 172-177

18. Scherrer SS, de Rijk WG, Belser UC (1996) Fracture resistance of human enamel and three all-ceramic crown systems on extracted teeth. Int J Prosthodont 9, 580-585

19. Tsai YL, Petsche PE, Anusavice KJ, Yang MC (1998) Influence of glass-ceramic thickness on Hertzian and bulk fracture mechanisms. Int $\mathrm{J}$ Prosthodont 11, 27-32

20. Castelnuovo J, Tjan AHL, Phillips K, Nicholls JI, Kois JC (2000) Fracture load and mode of failure of ceramic veneers with different preparations. J Prosthet Dent 83, 171-180

21. Wuttiphan S, Lawn BR, Padture NP (1996) Crack suppression in strongly bonded homogeneous/ heterogeneous laminates: a study on glass/glassceramic bilayers. J Am Ceram Soc 79, 634-640

22. Lee KS, Wuttiphan S, Hu XZ, Lee SK, Lawn BR (1998) Contact-induced transverse fractures in brittle layers on soft substrates: a study on silicone nitride bilayers. J Am Ceram Soc 81, 571-580

23. Jung YG, Wuttiphan S, Peterson IM, Lawn BR (1999) Damage modes in dental layer structures. J Dent Res 78, 887-897

24. Niihara K (1985) Indentation microfracture of ceramics - Its application and problems. Seramikkusu 20, 12-18 (in Japanese)

25. Lawn BR, Swain MV (1975) Microfracture beneath point indentations in brittle solids. J Mater Sci 10, 113-122

26. Yamamoto M, Matsui T, Murakami H, Kimura K, Niwa K, Ito Y (2002) Stress distribution analysis of all ceramic crown in chewing food - Noticed diopside -. Aichi-Gakuin Daigaku Shigakkai Shi 40, 373-380 (in Japanese)
27. Deng Y, Miranda P, Pajares A, Guiberteau F, Lawn BR (2003) Fracture of ceramic/ceramic/polymer trilayers for biomechanical applications. J Biomed Mater Res A 67, 828-833

28. Kelly JR, Campbell SD, Bowen HK (1989) Fracturesurface analysis of dental ceramics. J Prosthet Dent $62,536-541$

29. Kelly JR, Giordano R, Pober R, Cima MJ (1990) Fracture surface analysis of dental ceramics: clinically failed restorations. Int J Prosthodont 3, 430440

30. Harvey CK, Kelly JR (1996) Contact damage as a failure mode during in vitro testing. J Prosthodont 5, 95-100

31. Jung YG, Peterson IM, Kim DK, Lawn BR (2000) Lifetime-limiting strength degradation from contact fatigue in dental ceramics. J Dent Res 79, 722-731

32. Peterson IM, Wuttiphan S, Lawn BR, Chyung K (1998) Role of microstructure on contact damage and strength degradation of micaceous glassceramics. Dent Mater 14, 80-89

33. Drummond JL (2003) Ceramic behavior under different environmental and loading conditions. In Dental materials in vivo: aging and related phenomena. Eliades G, Eliades T, Brantley WA, Watts DC eds, Quintessence Publishing, Carol Stream, 35-45

34. Zhang Y, Song JK, Lawn B (2005) Deep-penetrating conical cracks in brittle layers from hydraulic cyclic contact. J Biomed Mater Res B Appl Biomater 73, 186-193

35. Zhang Y, Lawn B (2005) Competing damage modes in all-ceramic crowns: fatigue and life time. Key Eng Mater 284-286, 697-700 